META-ANALYSIS

\title{
A META-ANALYSIS OF PHARMACOLOGICAL AND ALLIED THERAPY IN CHILDREN WITH ADHD
}

\begin{abstract}
Attention Deficit Hyperactivity Disorder (ADHD) is a behavioral disorder of childhood, having neurogenic origin. Children with ADHD are characterized by lack of focus and attention on tasks that typically developing children are able to perform. The increased prevalence of ADHD globally may be attributed to increased awareness of the condition in society, and also its genuine rise in children. The prevalence of children with ADHD at CSLHS estimates to four per month. These children warrant treatment by a team of medical and allied health professionals who are psychologists, neurologists, pediatricians, behavior therapist, occupational and speech-language therapists and remedial educationists. A meta-analysis was carried out to review three clinical trials conducted in developed countries that addressed the efficacy and effectiveness of stimulant and non-stimulant drugs given to children with ADHD, in concomitance with behavior therapy.
\end{abstract}

Medication along with the allied therapy services presented globally better results in the children with ADHD, with fulfilled educational needs and improved quality of life for their families.

Appropriate attentional skills, are a key pre-requisite for acquisition and learning of communication skills in all modalities, which manifest a child's academic success, through childhood and adolescence. Further, children presenting with ADHD are challenged by the dearth of early intervention in developing countries; hence an appropriate combination of pharmacological, behavior therapy along with parent and teacher training can lead to their successful rehabilitation.

\section{Keywords}

Attention Deficit Hyperactivity Disorder, pharmacological treatment, stimulants, non-stimulants, speech therapy, early intervention, behavior therapy.

\section{Maha Khalid}

Student of BS SLT

College Of Speech Language And Hearing Sciences (CSLHS) Ziauddin University mahakhalid31@gmail.com

\section{Amina Asif Siddiqui}

Assistant Professor

College of Speech Language And Hearing Sciences (CSLHS) Ziauddin University amina.siddiqui@zu.edu.pk

\section{Tahoora Javed Chandna}

Student of BS SLT

College of Speech Language And Hearing Sciences (CSLHS) Ziauddin University tahoorajaved@gmail.com

[ Khalid M, Siddiqui AA, Chandna TJ. A Meta-analysis of pharmacological and allied therapy in children with ADHD; Pak. j. rehabil. 2015;4(1) 4-11] 


\section{INTRODUCTION}

\section{Background}

Attention Deficit Hyperactivity Disorder (ADHD) happens to be a very commonly occurring neurodevelopmental disorder in children in today's times, and is estimated to make $30-40 \%$ of referrals to child mental health practitioners'. The prevalence of this disorder in Pakistan has been found to be around $2.49 \% .^{2}$

$\mathrm{ADHD}^{3-5}$ is a chronic, debilitating disorder which affects millions of children and adults. It impacts several aspects of an individual's life, such as parent-child relationships, academics, as well as social and vocational skills. Children with ADHD struggle to make relationships with caregivers and other children, finding it difficult to take turns and play co-operatively. They might not be able to follow the class rules or adjust their behavior in different social situations, nor would they be able to express themselves to communicate their message across to others. Their impulsivity and lack of attention has a negative effect on their academic output, and hence functionality in the long run. All this manifests increase healthcare costs for the children and their families.

ADHD could be managed through an amalgamation of different treatment approaches, which include psycho - education, behavioral intervention, medication and dietary changes. The therapeutic approach is essential for the lifestyle modification necessary for the management of behavior. since most children with ADHD have problems across a wide spectrum, multimodal intervention is best recommended ${ }^{6,7}$. There are several types of drugs that are useful, and several medications within each type, have been used to treat the chemical imbalance existing in children who present with ADHD.

The idea of this meta-analysis is to essentially examine the results of several studies that reported either the same or very closely similar outcome so as to draw an estimate of the effect size for treatment. ${ }^{8}$

\section{The known causes of Attention Deficit Hyper- activity Disorder}

The exact etiology of ADHD is still under study. However, currently researchers have proposed several possible reasons, some of which are listed below.

- Genetic factors: Parents with one child having ADHD, increases the chance of having other off springs with this condition by $33 \%$ and a parent having ADHD increase the chances of passing it to the off spring by $50 \%$.

- Neurochemical Factors: An imbalance of the neurotransmitters dopamine and norepinephrine can cause hyperactivity and impulsivity.
- Psychosocial Factors: Beiderman ${ }^{10}$ hypothesized that family environment variables such as severe marital disturbances, large family size, maternal psychiatric disorder, are significant risk factors in the development of ADHD.

- Pre-mature birth: babies born pre-maturely are at a higher risk for developing ADHD.

The meta-analysis was conducted to see the efficacy and effectiveness of drugs categorized as stimulant drugs versus non-stimulant drugs that are given to children with ADHD, in concomitance with behavior therapy and/or other rehabilitation services.

\section{Terminology used in ADHD}

Attention Deficit Hyperactivity Disorder (ADHD) ${ }^{11}$ is understood to be the tenacious pattern of inattentiveness along with hyperactivity - impulsivity, that occur more often in some children as compared to their typically developing peers; such that it is regarded as 'severe.' The atypically developing counterparts are at an equivalent level of physical development and exhibit difficult behaviors in at least two settings, to an extent that it hinders their social and academic development. It could make a detrimental impact on their speech and language development as well.

The Diagnostic Statistical Manual-IV (DSM-IV), describes ADHD, ${ }^{12}$ as characterized by having a pattern of behaviors, that can be easily identified as different amongst children presenting with this condition, in various places (e.g. playgroups, and home), so as to affect the child's performance in social, educational, or other settings. In DSM-IV, symptoms are characterized into inattention or inattentiveness or an inability to focus consistently on tasks for a required or expected amount of time. Whilst hyperactivity and impulsivity include the child's inability to pay close attention to specifics, and difficulty in organizing the tasks and activities age appropriately. The child may talk excessively or talk out of turn, fidget constantly, or fail to remain in his seat in any given situation. In order to be diagnosed with ADHD the have a minimum of six symptoms from any one or both the groups of symptoms namely the inattention group of criteria and/or the hyperactivity and impulsivity criteria. Older children or adolescents and adults that are over the age of 17 years, must exhibit any five of the given characteristics. These symptoms must not better point out to any other disorder/condition.

Allied Health Services ${ }^{13}$ are a group of health service providers that consist of clinical laboratory personnel, physical and occupational therapists, nutritionists and dietetic services, medical record personnel, radiological services, speech language pathologists and audiologists, as well as respiratory therapists. General physicians, and other doctors, nurses, 
and dentists, orthodontists and prosthodontists are not included in this category. Allied health care providers are considered as the third pillar of health care service providers. The allied professionals are involved in providing direct consumer care, which includes diagnosis, treatment and rehabilitation to those in need.

Behavior Therapy ${ }^{14}$ has its bases in the theory of behaviorism, which emerged several years ago. This theory predominantly propagates the point of view that learning occurs because of the stimulation we receive from our environment. Behavior therapy is given to control or eliminate unwanted behaviors, and aims to achieve this by reinforcing desirable and acceptable behaviors and extinguishing unwanted and unacceptable ones. The strategies implemented in this type of treatment are based on the theories of classical conditioning and operant conditioning. Behavior therapy 15 is majorly focused on helping an individual understand that an alternate or different behavior can lead to changes in how they feel. This shall promulgate the idea that they must stay focused and involved in positive or socially and communicatively rewarding activities. Behavior therapy is an evidence based, and scientific approach that is designed to objectively measure the person's behavior, followed by carefully structured steps that are aimed at increasing his/her appropriate behavior, thereby making him/her an acceptable part of the society.

Speech language therapy ${ }^{16}$ focuses on a dichotomy of receptive language skills which is the ability to understand the spoken utterances of others; along with expressive language skills which is the ability to use grammatically correct verbal utterances, such as words and sentences to express oneself, in every context, using the right set of sounds or phonemes. Therefore, also deals with the mechanism of generating words, known as articulation. Speech must have a pleasant pitch, and intensity of voice, and should be spoken in a fluent manner. Provision of speech language therapy for adults is an essential part of the rehabilitation process following a Cerebro - Vascular Accident (CVA) commonly known as a stroke. An acquired language disorder could also occur after a traumatic brain injury (TBI) that detrimentally alters the persons' ability to comprehend and/or use language. In the younger population, it majorly involves achieving developmental milestones that have been delayed. Some children only require help with language, whilst others may have difficulties with the mechanical production of speech, whilst still others may need every kind of help that is possible with respect to verbal communication skills. Communication 17 is the act or process of using words, sounds, signs, or behaviors (including facial expressions, gestures and vocal intonation) to exchange as well as share information, or to express one's own thoughts, ideas, desires, needs and feelings with someone else.
Stimulants ${ }^{18}$ are a class of psychoactive drugs that enhance the neural activity. These drugs can temporarily improve or increase alertness, mood, and awareness. We must bear in mind that although it is legally permissible to use some stimulant drugs, all of them do have the potential to be addictive. Names of such stimulants are Cocaine, Amphetamines, and other prescription drugs.

Non-stimulants ${ }^{19}$ causes an increase in the amount of "norepinephrine," which is an important chemical in the brain. This increase has exhibited substantial improvement in children with ADHD, as it causes an increase in the required attention span and reduces impulsive behavior and hyperactivity. Atomoxetine $^{20}$ is known to be the most common non-stimulant drug that is prescribed by most physicians. It is a "selective norepinephrine (noradrenaline) reuptake inhibitor," that has not been classified as a stimulant drug, and is given to patients with ADHD when stimulants do not relieve symptoms or when they cause intolerable side effects. Atomoxetine is effective and well tolerated; data suggests that there is unlikely to be any potential of (drug) abuse in the users. ${ }^{21}$

\section{METHODOLOGY}

\section{Eligibility criteria}

For a study to be part of this meta-analysis, it had to meet the following criteria:

\section{Inclusion criteria}

i) The study could only contain children, aged 14 years and younger.

ii) Children of both genders were part of each study. iii) The sample could only include children who had been confirmed to have ADHD.

iv) The children in the study should have been diagnosed with ADHD in accordance to DSM -IV.

v) The performance of children in each study should have been reported by the teachers and/or parents.

vi) Randomized control trials evaluating the effect of medication on the condition were included.

vii) Studies included should have been conducted in the English language.

viii) The control groups received any treatment besides stimulants/non-stimulants.

\section{Exclusion criteria}

i) Any study which had a co-existing disorder (such as oppositional Defiant Disorder or Conduct Disorder) present with ADHD could not be considered. ii) Studies which did not have stimulant or non-stimulant treatment as an option were not included. iii) Studies that were conducted before 1995 were not a part of this meta-analysis. iv) Studies which included children aged 14 and above were not included. 


\section{Literature search}

Articles from January 2015 onwards were reviewed, for this meta analysis. Randomized control trials, the National Institute of Health, Pub Med, and articles from the Journal of Psychiatry, India, the JAMA network, official journal of the American Academy of Pediatrics were some sources used to search for relevant articles on the electronic media.

\section{Study selection and data extraction}

12 articles were extracted from the electronic media, after finding relevance to the topic by reading the abstract. A thorough review of those 12 studies, closely relevant to this meta-analysis, was made. Reviewers searched the studies to evaluate for the suitability of the inclusion criteria. However, out of the 12 studies only 3 were carefully chosen, whilst 9 studies were excluded after a comprehensive review, as their focus in the study deviated from effect of the treatment on the symptoms of the disorder itself.

\section{Procedure}

3 studies were selected, and closely analyzed, from a wide range of studies which had to meet the eligibility criteria set by the reviewers. Studies used are:

1. A 14-Month Randomized Clinical Trial of Treatment Strategies for Attention-Deficit Hyperactivity Disorder ${ }^{22}$

2. Comparative Short term Efficacy and Tolerability of Methylphenidate and Atomoxetine in Attention Deficit Hyperactivity Disorder. ${ }^{23}$

3. Once-Daily Atomoxetine Treatment for Children and Adolescents with Attention Deficit Hyperactivity Disorder: A Randomized, Placebo-Controlled Study ${ }^{24}$.

\section{Statistical analysis}

In this meta-analysis, the finding of the studies is converted into an effect size, a common metric for all the studies. The effect size was estimated by standardized mean difference (d). ${ }^{25}$

The following tables (Table1, Table 2 and table 4) summarize the effect of medication, while table 3 illustrates the effect of combined treatment on hyperactivity and inattention with the varying values of " $d$ ".

\begin{tabular}{|l|l|l|l|}
\hline \multicolumn{2}{|l|}{$\begin{array}{l}\text { Table 1: The standard mean } \\
\text { difference showing the effect of } \\
\text { medication on hyperactivity }\end{array}$} & $\begin{array}{l}\text { Standardized } \\
\text { Mean } \\
\text { Difference(d) }\end{array}$ \\
\hline Study 1 & Atomoxetine & $\begin{array}{l}\text { Hyper } \\
\text { activity }\end{array}$ & -1.70 \\
\hline Study $\mathbf{2}$ & Atomoxetine & $\begin{array}{l}\text { Hyper } \\
\text { activity }\end{array}$ & -2.88 \\
\hline Study $\mathbf{3}$ & $\begin{array}{l}\text { Medication } \\
\text { management }\end{array}$ & $\begin{array}{l}\text { Hyper } \\
\text { activity }\end{array}$ & -1.58 \\
\hline
\end{tabular}

\begin{tabular}{l|l} 
Table 2: The standard mean \\
difference showing the effect of \\
medication on inattention
\end{tabular}$\quad \begin{aligned} & \text { Standardized } \\
& \text { Mean } \\
& \text { Difference(d) }\end{aligned}$

\begin{tabular}{|l|l|l|l|}
\hline Study 1 & Atomoxetine & Inattention & -1.70 \\
\hline Study $\mathbf{2}$ & Atomoxetine & Inattention & -2.88 \\
\hline Study $\mathbf{3}$ & $\begin{array}{l}\text { Medication } \\
\text { management }\end{array}$ & Inattention & -1.58 \\
\hline
\end{tabular}

\begin{tabular}{|c|c|}
\hline \multicolumn{2}{|c|}{ Table 3 Combined treatment } \\
\hline & Standard mean difference (d) \\
\hline Hyperactivity & -1.69 \\
\hline Inattention & -0.87 \\
\hline
\end{tabular}

Table 3: the standard mean difference showing the effect of combined treatment on hyperactivity and inattention

\begin{tabular}{|c|c|c|}
\hline Table 4 & \multicolumn{2}{|c|}{$\begin{array}{c}\text { Overall Estimates } \\
\text { (Study1 + Study2 + Study3) }\end{array}$} \\
\hline & Mean & $\begin{array}{c}\text { Standard } \\
\text { Deviation }\end{array}$ \\
\hline Hyperactivity & -2.05 & -0.71 \\
\hline Inattention & -2.93 & -2.06 \\
\hline
\end{tabular}

Table 4: Mean and standard deviation of 3 studies showing the effect of medication on hyperactivity and inattention.

\section{DISCUSSION}

The standardized mean difference, was calculated as the effect size, it expresses the size of the intervention effect in each study relative to the variability observed in that study. ${ }^{26}$ All 3 studies showed significant improvement with medication, having the greatest effect on the hyperactivity component out of the two. The combined treatment had the greatest outcome compared to the medication therapy alone. The reduction in values indicates that medication therapy along with rehabilitation services had a positive effect on the clinical symptoms of the disorder. The mean of all 3 studies indicates substantial difference in both hyperactivity and inattention.

\section{RESULTS}

The 3 studies chosen on the basis of similar baseline are described in the table 5.

It is recommended that a multidisciplinary team provides treatment of ADHD in all age groups, because combined treatment was superior to either 
Table 5

\begin{tabular}{|c|c|c|c|}
\hline Study-Author & Objective & Result & Conclusion \\
\hline $\begin{array}{l}\text { A 14-Month } \\
\text { Randomized } \\
\text { Clinical Trail of } \\
\text { Treatment } \\
\text { Strategies for } \\
\text { Attention-Deficit/ } \\
\text { Hyperactivity } \\
\text { Disorder } \\
\text {-MTA Cooperative } \\
\text { Group }\end{array}$ & $\begin{array}{l}\text { "To determine the } \\
\text { effectiveness of } \\
\text { pharmacotherapy and } \\
\text { behavior therapy given to } \\
\text { children with ADHD, over a } \\
\text { long term, which was } \\
\text { defined as being a period } \\
\text { greater than } 4 \text { months. } \\
\text { Results were obtained over } \\
3 \text { arms of the study; wich } \\
\text { were also compared with } \\
\text { children receiving } \\
\text { community health services. } \\
\text { The } 3 \text { arms were } \\
\text { Medication treatment, } \\
\text { Behavior therapy and } \\
\text { Combined Treatment, } \\
\text { which included children } \\
\text { receiving medication and } \\
\text { behavior therapy } \\
\text { simultaneously." }\end{array}$ & $\begin{array}{l}\text { "Medication management } \\
\text { treatment amd Combine } \\
\text { treatment did not differ } \\
\text { significantly on any direct } \\
\text { comparisons. } \\
\text { In several instances (opposiyional/ } \\
\text { aggresive symptoms, Internalizing } \\
\text { symptoms, teacher rated social } \\
\text { skills, parents- child relations, and } \\
\text { reading achivement) combined } \\
\text { treatment proved superior to } \\
\text { intersive behavioral treatment } \\
\text { and/or community care while } \\
\text { medication management did not. } \\
\text { Study medication strategfies were } \\
\text { superior to community care } \\
\text { treatments, despite the fact that } \\
\text { two thirds of community-treated } \\
\text { subjects received medication during } \\
\text { the study period." }\end{array}$ & $\begin{array}{l}\text { "Carefully crafted } \\
\text { medication management } \\
\text { was superior to behavioral } \\
\text { treatment and to routine } \\
\text { community care that had } \\
\text { included medication. } \\
\text { Combined treatment did } \\
\text { not yield significantly } \\
\text { greater benefits than } \\
\text { medication management } \\
\text { for core Attention Deficit } \\
\text { Hyperactivity Disorder } \\
\text { symptoms } \\
\text { Combined treatment may } \\
\text { have provided modset } \\
\text { advantages for non-ADHD } \\
\text { symptom and positive } \\
\text { functioning outcomes." }\end{array}$ \\
\hline $\begin{array}{l}\text { Comparative Short } \\
\text { term Efficacy and } \\
\text { Tolerability of } \\
\text { Metrhylphenidate } \\
\text { and Atomexetine } \\
\text { in Attention Deficit } \\
\text { Hyperactivity } \\
\text { Disorder } \\
\text { JASMIN GARG, } \\
\text { PRITI ARUN AND } \\
\text { BS CHAVAN }\end{array}$ & $\begin{array}{l}\text { "Compare the short term } \\
\text { efficacy and tolerability of } \\
\text { methylphenidate and } \\
\text { automoxetine in children } \\
\text { with ADHD" }\end{array}$ & $\begin{array}{l}\text { "Response was observed in } 90.7 \% \\
\text { patients from the methylphenidate } \\
\text { group on average dose od } 0.45 \\
\mathrm{mg} / \mathrm{kg} / \mathrm{d} \\
\text { Response was observed in } 86.2 \% \\
\text { patients of the atomoxetine group } \\
\text { at an average dose of } 0.61 \mathrm{mg} / \mathrm{kg} / \mathrm{d} \\
\text { Comparable improvement observed } \\
\text { on VADPRS ( } \mathrm{P}=0.500), \mathrm{VADTRS} \\
\text { ( } \mathrm{P}=0.264 \text { ) and CGI-S (P=0.997). } \\
\text { Weight loss was significantly higher } \\
\text { in methylphenidate group (-0.57+0.78 } \\
\mathrm{kg} ; \mathrm{P}=0.001 \text { ) } \\
\text { Heart rate increase was observed at } \\
\text { higher rate in atomoxetine group } \\
\text { (7+9bpm; } \mathrm{P}=0.021) . "\end{array}$ & $\begin{array}{l}\text { "Methylphenidatre and } \\
\text { atomoxetine are } \\
\text { efficacious in indian } \\
\text { children with ADHD at } \\
\text { lesse doses than } \\
\text { previously used. } \\
\text { Their efficacy and } \\
\text { tolerability are } \\
\text { comparable." }\end{array}$ \\
\hline $\begin{array}{l}\text { Once-Daily } \\
\text { Atomoxetine } \\
\text { Treatment for } \\
\text { Childern and } \\
\text { Adolescents With } \\
\text { Attention Deficit } \\
\text { Hyperactivity } \\
\text { Disorder: A } \\
\text { Randomized, } \\
\text { Placebo- } \\
\text { Controlled Study } \\
\text { David Michelson, } \\
\text { M.D et.al }\end{array}$ & $\begin{array}{l}\text { "The efficiency of once-daily } \\
\text { atomoxetine administration } \\
\text { in the treatment of children } \\
\text { and adolescents with } \\
\text { attention deficit } \\
\text { hyperactivity disorder } \\
\text { (ADHD)" }\end{array}$ & $\begin{array}{l}\text { "Outcomes among atomoxetine- } \\
\text { treated patients were superior to } \\
\text { those of the placebo treatment } \\
\text { group as assessed through } \\
\text { investigator, parent, and teacher } \\
\text { ratings" }\end{array}$ & $\begin{array}{l}\text { "Once- daily } \\
\text { administration of } \\
\text { atomoxetine is an effective } \\
\text { treatment for children and } \\
\text { adolescents with ADHD" }\end{array}$ \\
\hline
\end{tabular}


treatment alone. Such a multimodal approach would include administering medication along with psychosocial management strategies, and educational interventions. ${ }^{27}$

One study concludes that lower doses of medication have similar effects as with the increased dose. Medication has been seen to have favorable effects on the disorder however; the results of combined treatment outweigh the medication treatment alone. Therefore, combined treatment is a superior option to deal with the symptoms of the ADHD, in young children.

\section{Study characteristics}

1) Participants: Children aged between 6 - 14 years, both male and female were sampled in the three studies that were analyzed for this article. All the children had been diagnosed to have ADHD and had received a combination of treatments or at least medication which were either stimulants and/or non-stimulants.

2) Sample size: a total of 12, 520 children were sampled in the three studies that were selected for this meta-analysis.

3) Diagnosis: The DSM-IV criteria are the minimum necessary norm for the diagnosis of ADHD; therefore the 12,520 children selected in the three studies used for this meta-analysis were diagnosed with ADHD according to the Diagnostic and Statistical Manual IV (DSM - IV). Participants included in all 3 studies had to have no other co-existing condition with ADHD such as oppositional defiant disorder, schizophrenia and clinical depression etc.

4) Treatment: In all the three studies, medication management was a treatment option, either stimulants or non-stimulants, given along with other choices of treatment such as any of the therapy services.

5) Outcome measure: All studies indicated comparable differences among drug treatments. Combined treatment showed the greatest improvement. The improvement measured was either through standardized norm referenced tests and/or teacher and parent reviews.

\section{STUDY LIMITATIONS}

- A varying age group of participants was studied, which may not enable us to understand the degree of effectiveness of combined therapy on children of a specific age, particularly those receiving early intervention which is known to provide best prognosis.

- The sample size of the three studies varied and overall the sample size was diminutive, with only 12 , 520 children in total.
- Hyperactivity and inattention were the two behaviors which were measured in all three studies, whilst the other skills/behaviors taken in focus in one study were not targeted in the others such as academic performance.

- Type of allied therapy services provided to children in each study differed from the other and one study did not include any form of allied therapy

- Standard mean difference was the effect size measured, one of the limitations of the effect size is that there is no acknowledged threshold to establish the considerable difference between two groups. ${ }^{28}$ - Only 3 studies were a part of this meta-analysis, reducing the validity.

\section{CONCLUSION}

All three studies in this meta - analysis emphasize the role of medical management for children with ADHD. However, after composing the results of each study in our meta-analysis we may conclude that medication alone is not sufficient for overcoming any or all of the major symptoms of ADHD in children; they may help in surmounting the associated behaviors we see with this disorder in whose presence, behavior management through allied therapy is largely ineffective. Also, the effects of medical management can also be observed in children to the same degree given lower doses of the stimulant/non-stimulant drugs. The improvement was reported by either the teacher and/or parents. Hence a combination of pharmacological and behavioral management could provide holistic and better results.

\section{Conclusion with relevance to Pakistan}

At least 4 children are seen with ADHD at the CSLHS clinic, Ziauddin University, in Karachi. Through extensive research it has been gathered that geographic location plays a limited role in the reasons for the large variability of ADHD prevalence worldwide. ${ }^{4}$ There is paucity of research that has been done on the population of Pakistan. Most caregivers including parents and school teachers lack awareness and often do not get the child assessed at an earlier age. Parents who do get their child evaluated are often in a dilemma for the right choice of treatment. This meta-analysis aims to analysis aims to analysis aims to analysis aims to analysis aims to analysis aims to analysis aims to help in help in help in help in help in counseling parents and professionals who deal with children with ADHD for the best management, and that too as early as possible for a better quality of life.

\section{RECOMMENDATIONS:}

All professionals namely educationalists, primary and specialist health care providers, support service 
personnel, medical and allied health personnel that engage with children who have been diagnosed with ADHD, should connect with one another, for treatment strategies yielding better results. ${ }^{29}$ Behavioral interventions and allied therapy services should be provided to the children within the school; as these are known to be effective in reducing Khalid $M$ et al. A Meta-analysis of pharmacological and allied therapy in children with ADHD Pakistan Journal of Rehabilitation 2015 Volume 4 (Issue 1) Page 13 hyperactivity as well as help in building attention, and help in adjustment within the socio communicative environment, leading to better acceptance and performance in larger realms. ${ }^{30}$ Early intervention can markedly reduce those symptoms, ${ }^{31}$ hence reduced social and emotional stress, $^{32}$ therefore teachers of pre-school children must receive training to detect symptoms in the early years.

Additionally it is also recommended to conduct further research in medical management of children with ADHD in Pakistan to ascertain and establish the existence of pharmacodynamics and pharmacokinetic differences among children belonging to the Indian race versus the other ethnicities in different regions of the world. ${ }^{33}$

Further research is also recommended to establish the efficacy of combination therapies in Pakistan and the hurdles therein.

\section{REFERENCES}

[1] Imran Nazish. Pak J Med Sci January - March 2007 Vol. 23 No. 1 9-15

[2] Karim R., Shakoor A, Azhar L, Ali A. Prevalence and Presentation of ADHD among the attendees of Child Psychiatric Clinic. Mother \& Child 1998;36(1):71-5.

[3] Lynn Marks. Medications to Treat ADHD- Everyday guide to ADHD, last updated 1/4/2016.Available from: http://www.everydayhealth.com/adhd/adhd-drugs.aspx

[4] Guilherme P, Mauricio S L, Bernardo L, Joseph BL Augusto R. The Worldwide Prevalence of ADHD: A Systematic Review and Metaregression Analysis; The American Journal of Psychiatry Volume 164, issue 6; pages 942-948; June 2007; Available from: http://ajp.psychiatryonline.org/doi/abs/10.1176/ajp.2007.164.6.942

[5] Louis S M, 1 Clark $P, 1$ and Manishi P1 A review of the economic burden of ADHD; BioMed Central Ltd. 2005 June 9; Available from: 10.1186/1478-7547-3-5

[6] NICE guidelines for diagnosis and the treatment of ADHD. (2002). United Kingdom. Available from; https://www.nice.org.uk/guid$\mathrm{a} \mathrm{n}$ c e / c g 72 / e v i dence/adhd-full-guideline-241963165.

[7] Pelham WEl et.al, Transdermal methylpheni- date, behavioral, and combined treatment for children with ADHD, Exp Clin Psychopharmacol. 2005 May; 13(2):111-26; Available from: http://www.ncbi.nlm.nih.gov/pubmed/15943544.

[8] Ryan R; Cochrane Consumers and Communication Review Group. 'Cochrane Consumers and Communication Review Group: meta-analysis. April 2015, pl; available from:http://cccrg.cochrane.org.

[9] Breslau N, Brown GG, DelDotto JE, Kumar S, et al; Psychiatric Sequelae of low birth weight at 6 years of age; Journal of Abnormal Child Psychology, volume 24, Issue 2, Pages 385-400, June 1996; Available from: http://link.springer.com/article/10.1007\%2FBF01441637

[10] Biederman J, Milberger S, Faraone SV. Family-environmental risk factors for ADHD. Arch Gen Psychiatry; volume52(6): pages 464-70, June 1995; Available from: http://www.ncbi.nlm.nih.gov/pubmed/7771916.

[11] Singh S, Kent R. Singular's dictionary of speechlanguage pathology. San Diego: 2000. p21

[12] American Psychiatric Association, The Diagnostic and Statistical Manual for Mental Disorders, (4th edition, text revised). Washington, DC: 2000.

Miller-Keane Encyclopedia and Dictionary of [13] Medicine, Nursing, and Allied Health [Internet], 7th ed.: Saunder; 2003. Available from: (http://medical-dictionary.thefreedictionary.com/Allied+health+professions)

[14] Cherry, K.A. What is behavioral therapy? - Theories and quiz [published lecture notes on the Internet], (2012). About health: types of psychotherapy. Psychology.about.com (online) Retrieved from http://psychology.about.com/od/typesofpsychotherapy/a/behavioral-therapy.htm

[15] Herkov, M. About Behavior Therapy. Psych Central. (2013). [cited 2015 April 17] Available from http://psychcentral.com/lib/about-behavior-therapy/000669

[16] Mauro T, what is speech therapy?-(2015, June 20). About.com (online) available from (http://specialchildren.about.com/od/speechtherapy/g/SLP.htm)

[17] Merriam Webster's dictionary (online) communication(2015 June). Merriam-Webster.com. Retrieved from (http://www.merriam-webster.com/dictionary/communication)

[18] National Institute on Drug Abuse. [Updated 2008, July 22; cited 2015 May 12]. Prescription Drugs: Abuse and Addiction. Available from http://www.nida.nih.gov/ResearchReports/Prescription/Prescription4.html

[19] WebMD Medical reference-non stimulant drug therapy for ADHD. 2015, Available from http://Www. webmd.com/add-adhd / g u i d e / a d h d - non stimu lant-drugs-therapy? page $=5$

[20] Garnock J, Keating GM. Atomoxetine: a review 
of its use in attention-deficit hyperactivity disorder in children and adolescents. US National Library of Medicine National Institutes of Health. November 2009, 11 (3):203-2; Available from: $\quad$ http://www.ncbi.nlm.nih.gov/pub$\mathrm{med} / 19445548$

[21] Garnock Jones, Keating GM. Atomoxetine: a review of its use in attention-deficit hyperactivity disorder in children and adolescents. US National Library of Medicine National Institutes of Health. November 2009, 11 (3):203-26; Available from: $\quad$ http://www.ncbi.nlm.nih.gov/pub$\mathrm{med} / 19445548$

[22] MTA Cooperative Group. A 14-Month Randomized Clinical Trial of Treatment Strategies for Attention-Deficit/ Hyperactivity Disorder. Arch Gen Psychiatry. 1999;56(12):1073-1086; Available from: http://archpsyc.jamanetwork.com/article.aspx? articleid=205525\#

[23] Jasmin G, Priti A AND Chavan B. Comparative Short term Efficacy and Tolerability of Methylphenidate and Atomoxetine in Attention Deficit Hyperactivity Disorder. Indian Pediatr. 2014 Jul;51 (7):550-4; Available from: http://www.ncbi.nlm.nih.gov/pubmed/25031133

[24] David M, M.D et.al. Once-Daily Atomoxetine Treatment for Children and Adolescents With Attention Deficit Hyperactivity Disorder: A Randomized, Placebo-Controlled Study; Am J Psychiatry 2002; 159:1896-1901; Available from: http://ajp.psychiatryonline.org/doi/pdf/10.1176/appi.ajp.159.11.1896

[25] Australian Guidelines on Attention Deficit Hyperactivity Disorder[homepage on internet], [updated 2009 May, cited 2015 May 17]; Available from: http://www.nhmrc.gov.au/_files_nhm$\mathrm{rc} / \mathrm{p} \cup \mathrm{b} / \mathrm{i} \mathrm{c} a+\mathrm{i} O \mathrm{~ns} / \mathrm{a} \dagger+\mathrm{a} \mathrm{ch}$ ments/ch54_draft_guidelines.pdf

[26] Cooper, H. \& Rosenthal, R. 2006, American psychological association. Statistical versus traditional methods for summarizing research findings. Psychological Bulletin, 87, 442-449: Available from: http://www.sciencedi$\mathrm{r} e \mathrm{c} \dagger$. com/scie nce/arti -

\section{cle/pii/0191765X80900087}

[27] Julian PT Higgins and Sally G. Cochrane Handbook for Systematic Reviews of Interventions; The Cochrane Collaboration; 2011

[28] Dongsheng $Y$ and Jarrod E. D. A unified approach to measuring the effect size between two groups using SAS. Paper 335-2012; Available from: http://support.sas.com/resources/papers/proceedings 12/335-2012.pdf.

[29] H. Ayyash, S. Sankar, H. Merriman, C. Vogt, T. Earl, K. Shah, S. Banerjee, "Multidisciplinary consensus for the development of ADHD services: the way forward", Clinical Governance: An International Journal, 2013, Vol. 18 Issue: 1 pp. 30 - 38; Available from: http://www.emeraldin$\mathrm{s} \quad \mathrm{i} g \mathrm{~h}+\mathrm{c}$. $\mathrm{c} \quad \mathrm{m} / \mathrm{m} /$ doi/abs/10.1108/14777271311297939?journalC ode $=$ cgij.

[30] Austin VL. Pharmacological interventions for students with ADD. Intervention in School Clinic 2003 May;38:289-96; Available from: http://eric.ed.gov/? id=EJ667973.

George J. DuPaul, Lee Kern, Matthew J. Gormley, Robert J. Volpe; Early Intervention for Young Children with ADHD: Academic Outcomes for Responders to Behavioral Treatment, School Mental Health, Volume 3, Issue 3, pages 117-126,September 2011.

[31] Peter C Denái $M$, Ward $S, 1$ Khaled $S, 1$ and Joseph J, Social and emotional difficulties in children with ADHD and the impact on school attendance and healthcare utilization; Child Adolesc Psychiatry Ment Health. 2012; 6: 33. Published online 2012 October 4. Available from: http://www.ncbi.nlm.nih.gov/pmc/articles/PMC3489829/.

[32] Bakare MO, A hypothesis - Effective therapeutic dosage of antipsychotic medications in patients with psychotic symptoms: Is there a racial difference?, the Bio Medical Central Research Notes, (Open Access); 2008 Jun, 1:25, Available from : http://www.biomedcentral.com/1756-0500/1/25 